\title{
Influence of the CO Adsorption Environments on its Reactivity with (111) Terrace Sites in Stepped Pt Electrodes under Alkaline Media
}

\author{
Manuel J.S. Farias, Carlos Busó-Rogero, Rubén Gisbert, Enrique Herrero*, Juan M. Feliu* \\ Departamento de Química-Física, Instituto de Electroquímica, Universidad de Alicante \\ Apartado 99, E-03080, Alicante, Spain.
}

\begin{abstract}
The effect of the electrode potential in the reactivity of platinum stepped single crystal electrodes with (111) terraces towards $\mathrm{CO}$ oxidation has been studied. It is found that the $\mathrm{CO}$ adlayer is significantly affected by the potential at which the adlayer is formed. The electrochemical and FTIR experiments show that adsorbed CO layer formed in acidic solution at $\sim 0.03 \mathrm{~V} v s$. SHE is different from that formed at $-0.67 \mathrm{~V}$ vs. SHE in alkaline solutions. The major effect of the electrode potential is a change in the long-range structure of $\mathrm{CO}$ adlayer. The adlayer formed in alkaline media presents a higher number of defects. These differences affect the onset and peak potential for CO stripping experiments. The stripping voltammogram for the adlayer formed at $-0.67 \mathrm{~V}$ vs. SHE always shows a pre-wave and the peak potential is more negative than that observed for the adlayer formed at $0.03 \mathrm{~V}$ vs. SHE. This means that the apparent higher activity for $\mathrm{CO}$ oxidation observed in alkaline media is a consequence of the different $\mathrm{CO}$ adlayer structure on the (111) terrace, and not a true catalytic effect. The different behavior is discussed in terms of the different mobility of $\mathrm{CO}$ observed depending on the electrode potential. Also, the FTIR frequencies are used to estimate the pzc (potential of zero charge) for the $\operatorname{Pt}(111)$ electrode covered with a $\mathrm{CO}$ adlayer.
\end{abstract}

Keywords: Electrocatalysis; carbon monoxide; stepped Pt electrode; alkaline media, pzc.

*Corresponding author: E-mail addresses: herrero@ua.es (E. Herrero), juan.feliu@ua.es (J.M. Feliu). 


\section{Introduction}

In the field of electrocatalysis, the reactivity of platinum-based electrodes for the carbon monoxide oxidation reaction strongly depends on the history of the electrode surface as well as the applied potential at which the $\mathrm{CO}$ adlayer was formed. This phenomenon was firstly reported by Kita et al. in 1988. ${ }^{1}$ They observed that the voltammetric profile for CO stripping on a polycrystalline platinum electrode always exhibited a pre-oxidation wave that preceded the main $\mathrm{CO}$ electro-oxidation peak when electrode potentials for $\mathrm{CO}$ adsorption was held under the hydrogen adsorption/desorption region. On the other hand, when the electrode potentials for $\mathrm{CO}$ adsorption remained within the so-called double layer region, the stripping voltammetry corresponding to this $\mathrm{CO}$ adlayer did not exhibit the pre-oxidation wave and occurred in a single peak. Recently, ATR-SIERAS experiments indicate these differences are related to changes in the water-CO structure obtained at different dosing potentials. ${ }^{2}$

Although the physical origin (at a molecular level) of such changes are not known yet, it was soon realized that the potential for $\mathrm{CO}$ adsorption on platinum polycrystalline electrodes had a close relationship with the maximum $\mathrm{CO}$ coverage $\left(\theta_{\mathrm{CO}}\right)$ obtained on the electrode surfaces and with the kinetics of CO oxidation. ${ }^{3-5}$ In this way, the experimental conditions to reach the maximum $\mathrm{CO}$ surface coverage require the adsorption at a potential within the hydrogen underpotential deposition region $\left(\mathrm{H}_{\mathrm{upd}}\right)$, i.e., in potential range where hydrogen is adsorbed on the surface but there is no hydrogen evolution. This type of behavior is better studied and understood with platinum single crystal electrodes, since the surface structure is well known and in, some cases, ordered CO structures are formed upon adsorption. This is the case for the well-oriented $\operatorname{Pt}(111)$ electrode, for which two different structures were observed by in situ STM in the presence of CO in solution depending on the potential for $\mathrm{CO}$ adsorption $;{ }^{6}$ namely a $p(2 \times 2)-3 \mathrm{CO}$ with $\theta_{\mathrm{CO}}=0.75$ formed at $\sim 0.00 \mathrm{~V} v s . \mathrm{RHE}$, or a $(\sqrt{19} \times \sqrt{ } 19) R 23.4^{\circ}-13 \mathrm{CO}$ with $\theta_{\mathrm{CO}}=0.69$ at $0.25 \mathrm{~V}$. It is clear that none of 
those structures can be formed at a polycrystalline surface because long-range (111) domains are required to form those compressed and ordered $\mathrm{CO}$ structures. ${ }^{7}$ However, the knowledge gained with the single crystal electrodes is useful to understand the origin of preoxidation wave at a molecular level. The potential at which the $\mathrm{CO}$ adlayer was formed has a clear relationship with the $\mathrm{CO}$ coverage reached at those potentials and consequently with the $\mathrm{CO}$ oxidation kinetics. ${ }^{8-9}$ Regarding the oxidation mechanism, it was clear from the beginning that the CO oxidation reaction required the presence of adsorbed oxygenated species. ${ }^{10}$ The studies carried out with single crystal electrodes in acidic solution seem to indicate that the process occurs through the LangmuirHinshelwood mean field mechanism, ${ }^{11-12}$ which suggested that $\mathrm{CO}$ diffusion on the surface was fast. $^{13-14}$

The changes in the oxidation of CO depending on the adsorption potential in the SHE scale, are very clear when the voltammetric profile for the $\mathrm{CO}$ oxidation reaction in alkaline solutions is compared to that observed in acidic media. These differences were demonstrated by Koper and his co-workers for stepped surfaces containing (111) terrace sites. ${ }^{15-19}$ In alkaline media, several peaks appear for the oxidation of $\mathrm{CO}$ on those surfaces and a prewave is always present. In general, two main peaks (aside from the pre-wave) are observed in the voltammetry for stepped surfaces with (111) terraces. The one at higher potential appears in the same potential regions as the main peak for the $\mathrm{Pt}(111)$ electrode. The charge for the peak al lower potential is proportional to the step density and its peak potential depends on the site symmetry. ${ }^{15}$ These facts allow assigning each peak to a different surface site. That appearing at lower potentials was initially ascribed to the oxidation of $\mathrm{CO}$ adsorbed on low coordination sites (such as kink/step sites) because those sites can act as a center for nucleation of the oxygen-containing species that are required for $\mathrm{CO}$ oxidation. However, additional experiments indicated that the peak at low potentials corresponded 
to the $\mathrm{CO}$ oxidation adsorbed on terrace sites close to the step. ${ }^{16,20}$ The peak at higher potentials is then related to the oxidation of $\mathrm{CO}$ on the remaining terrace sites and on the step sites.

From the studies with stepped surfaces vicinal to the (111) pole, e.g., having (111) terraces, it can be considered that two different sites are present in a stepped surface when the CO oxidation reaction is considered: those very close to the step and the rest of the sites. The rate constant for the $\mathrm{CO}$ oxidation process in each site is potential dependent (following Butler-Volmer equation) and it is significantly higher for the sites close to the step for the same electrode potential. The $\mathrm{CO}$ oxidation process on each type of site ignites when the rate constant reaches a threshold value. At given potential, the rate constant for the sites close to the step will reach the threshold value and the CO molecules on those sites will be immediately oxidized. Then, two different situations appear depending on the $\mathrm{pH}$. At low $\mathrm{pH}$, the experimental evidence suggests that $\mathrm{CO}$ diffusion rate is fast (significantly faster than threshold value for the $\mathrm{CO}$ oxidation rate). ${ }^{9}{ }^{11-12} \mathrm{CO}$ molecules adsorbed on sites far from the step, whose $\mathrm{CO}$ oxidation rate constant is still below the threshold value for ignition, will immediately diffuse to the sites close to the step, where they are readily oxidized. These conditions give rise to only one peak in the voltammogram for the CO oxidation process, as has been experimentally observed. ${ }^{9}$ This voltammetric peak will have the contribution from the whole CO layer, but the oxidation has occurred exclusively on the sites close to the step. On the other hand, it is proposed that the $\mathrm{CO}$ diffusion rate in alkaline media is very slow. ${ }^{21}$ When the CO molecules adsorbed on sites close to the step are oxidized, the flow of $\mathrm{CO}$ molecules from sites far from the step reaching the activated sites is very small. To reach a significant oxidation rate for those molecules far from the step sites, the potential has to be increased so that the $\mathrm{CO}$ oxidation rate constant on remaining sites reaches the threshold value. Two voltammetric peaks are then obtained, one at low potentials with the contributions from the sites close to the step (and some 
from sites far from the step) and the one at higher potentials which contains the charge from oxidation of the remaining molecules.

Another important difference in the behavior of the alkaline solutions with respect to acidic media is that the prewave is usually present. The appearance of this prewave has been associated to the presence of defects in the $\mathrm{CO}$ adlayer which make the initial stages of $\mathrm{CO}$ oxidation easier. In this respect, Spendelow et al. ${ }^{22}$ showed that when a $\mathrm{CO}$ adlayer was formed on a $\operatorname{Pt}(111)$ electrode under a $0.1 \mathrm{M} \mathrm{NaOH}$ environment at $0.1 \mathrm{~V}$ vs. RHE and then transferred to a $0.5 \mathrm{M}$ $\mathrm{H}_{2} \mathrm{SO}_{4}$ solution, the corresponding voltammetric $\mathrm{CO}$ stripping always presented a preoxidation peak. In the reverse experiment, when the $\mathrm{CO}$ was adsorbed in acidic solution at $0.1 \mathrm{~V}$ vs. RHE and transferred to alkaline solutions, the prewave was absent. These experiments clearly suggest that the electrode potential has an important effect on the CO structure. In this respect, it has been shown that the $p(2 \times 2)-3 \mathrm{CO}$ structure, observed when $\mathrm{CO}$ is present on the solution, can be obtained both in acidic and alkaline solutions. ${ }^{23}$ However, there is a significant change in the size of the ordered domains, which are smaller in alkaline solutions. ${ }^{23-24}$ Since defects concentrate in the borders of the different ordered domains, the smaller the domains in the CO layer are, the larger amount of defects such layer contains. Incidentally, this interpretation supports the lower mobility of $\mathrm{CO}$ on $\mathrm{Pt}(111)$ electrodes in alkaline environments as compared to acidic media. Regarding the kinetics of the initial stages of the oxidation processes, it was clear from the beginning that they did not followed Langmuir- Hinshelwood kinetics, which lead to suggest that the oxidation mechanism for those initial stages followed Eley-Rideal mechanism. ${ }^{11}$ This oxidation mechanism has also been proposed for the oxidation of the prewave in alkaline solutions. ${ }^{25}$

All the previous results indicate that the electrode potential can have an important effect on the $\mathrm{CO}$ adlayer structure and its oxidation kinetics. To explore this effect, a detailed study of $\mathrm{CO}$ oxidation on stepped $\mathrm{Pt}(\mathrm{s})[(n-1)(111) \times(110)]$ electrodes has been carried out in alkaline and acidic 
media. We will show that the structure of the CO adlayer with (111) terrace sites in stepped $\mathrm{Pt}$ electrodes is strongly influenced by the solution $\mathrm{pH}$ at which the $\mathrm{CO}$ adlayer was formed, whereas the reactivity for $\mathrm{CO}$ oxidation in both media is very similar, provided that the $\mathrm{CO}$ adlayer have the same characteristics.

\section{Experimental}

Platinum single crystal electrodes were prepared according to Clavilier technique ${ }^{26}$ flame annealed and cooled down in $\mathrm{H}_{2}+$ Ar controlled atmosphere, which assures that the surface topography is in agreement with the nominal values. ${ }^{27}$ The single crystal surfaces used in this work were the $\operatorname{Pt}(111)$ electrode and its vicinal surfaces containing (110) monoatomic steps. The notation of these electrodes is $\operatorname{Pt}(n+1, n+1, n-1) \equiv \operatorname{Pt}(\mathrm{s})[(n-1)(111) \times(110)]$, where $n-1$ denotes the number of atomic rows on the (111) terrace parallel to the (110) monoatomic steps. The electrode areas are between 3 and $5 \mathrm{~mm}^{2}$ for the electrodes used in cyclic voltammetry and chronoamperometry, whereas in IR experiments the areas are ca. $11-13 \mathrm{~mm}^{2}$. Experimental details are given elsewhere ${ }^{20}$, namely, a three-electrode cell equipped with a platinum counter electrode and reversible hydrogen electrode (RHE) was used. All the electrode potentials in this work are quoted vs. RHE unless otherwise stated. It should be noted that the RHE scale is a pH dependent scale and it is useful for studying processes whose equilibrium potential is also $\mathrm{pH}$ dependent, such as $\mathrm{CO}$ oxidation. Thus, the RHE scale shifts with $\mathrm{pH}$ in the same way that the equilibrium potential for the studied processes, which facilitates the interpretation of the results. However, other important parameters in the interfacial properties, i.e., the interfacial charge, are dependent on the standard thermodynamic scale in electrochemistry, the SHE scale. Thus to study the effects of the electrode potential and the interfacial charge in the process, the values in the RHE scale should be converted 
in the SHE scale. To avoid misunderstandings between both scales, we will term that potential as the SHE potential.

The electrode potentials were controlled using a waveform generator (EG\&G PARC 175) together with a potentiostat (Amel 551) and a digital recorder (eDAC ED 401). Solutions were prepared using $\mathrm{NaOH}$ (Merck KGaA, $99.99 \%$ ), $\mathrm{H}_{2} \mathrm{SO}_{4}$ (Merck, Suprapur), $\mathrm{HClO}_{4}$ (Merck, suprapur) and ultrapure water (18.2 $\mathrm{M} \Omega \mathrm{cm})$. Ar (N50, Air Liquide) was used for deoxygenating the solutions. $\mathrm{CO}$ (N50, Air Liquide) adlayers were always formed at $0.1 \mathrm{~V}$ from saturated solutions. After forming the adlayer, $\mathrm{CO}$ was purged from the solution by bubbling Ar for 15 min, and the $\mathrm{CO}$ stripping voltammogram is recorded in the same solution. In some cases, $\mathrm{CO}$ was dosed at $0.1 \mathrm{~V}$ in a $\mathrm{H}_{2} \mathrm{SO}_{4}$ solution, transferred to a cell containing a $0.1 \mathrm{M} \mathrm{NaOH}$ solution, immersed at $0.1 \mathrm{~V}$, and finally recording the CO stripping voltammogram in this latter solution. Charge densities were corrected for the adsorption of anions. ${ }^{28}$

In situ FTIRS spectra were registered using a Nicolet (Model 8700) spectrometer, equipped with a MCT detector. The spectroelectrchemical cell was equipped with a $\mathrm{CaF}_{2}$ prism beveled at $60^{\circ}{ }^{29-30}$ One hundred interferograms with a resolution of $8 \mathrm{~cm}^{-1}$ were collected for each spectrum using $p$-polarized light. Spectra was acquired in a $25 \mathrm{mV}$ sampling interval from $0.05 \mathrm{~V}$ to $0.70 \mathrm{~V}$. Reference spectra was collected at $0.90 \mathrm{~V}$. At this potential value, the $\mathrm{CO}$ adlayer has been completely oxidized. The spectra are presented in absorbance units as $\mathrm{A}=-\log \left[\left(R_{1}-R_{2}\right) / R_{1}\right]$, where $R_{2}$ and $R_{1}$ are the reflectance values for the single beam spectra recorded at the sample and the reference potential, respectively. Positive bands in the spectra correspond to species present at the interface at the sample potential, whereas negative bands are linked to species at the interface at the reference potential but not at the sampling potential. 


\section{Results and discussions.}

\subsection{Electrochemical characterization of the surfaces in alkaline medium}

Cyclic voltammetric profiles for the $\operatorname{Pt}(111), \operatorname{Pt}(776)$ and $\operatorname{Pt}(554)$ electrodes in alkaline medium are displayed in Fig. 1. The characteristic features and the stability of the voltammograms upon cycling imply that the electrolyte solution is free of impurities. For $\operatorname{Pt}(111)$ electrode, the small feature at $0.40 \mathrm{~V}$ (positive going scan) indicates that electrode surface contains a small amount of defect sites with (100) symmetry as well as a similar amount of (110) defects at 0.26 $\mathrm{V} .{ }^{31}$ The integrated charge involved in these features is less than $1 \%$ of that related to the hydrogen adsorption on the (111) planes $\left(\sim 156 \mu \mathrm{C} \mathrm{cm}^{-2}\right)$. For the stepped surfaces, the sharp peaks appearing at $\sim 0.26 \mathrm{~V}$ (in the positive going scan) are associated with adsorption processes on the (110) step sites. ${ }^{31}$ In order to explain the higher activity for $\mathrm{CO}$ oxidation of the stepped surfaces in alkaline media, it has been proposed that these peaks correspond to a competitive adsorption process between $\mathrm{OH}$ and $\mathrm{H}$, so that the peak in the positive scan direction corresponds to the desorption of $\mathrm{H}$ from the step sites and the simultaneous adsorption of $\mathrm{OH}^{32}$ Moreover, the charge under these peaks is larger than that expected for hydrogen adsorption processes on the step sites, so it is clear that a competitive adsorption processes between hydrogen and additional species give rise to these peaks. ${ }^{33}$ Additionally, the complex potential dependence of the peak with the $\mathrm{pH}$ suggests that $\mathrm{O}$ is coadsorbed with $\mathrm{OH}$ in a ratio that depends on the $\mathrm{pH} \cdot{ }^{33}$

\subsection{Effect of adsorption potential and anion adsorption in $\mathrm{CO}$ oxidation}

Figure 2 shows the cyclic voltammograms for the oxidation of a $\mathrm{CO}$ layer adsorbed at $0.1 \mathrm{~V}$ on the $\operatorname{Pt}(111)$ surface. As can be seen, there is a clear dependence of the peak potential and sharpness on the anion present on the surface and the $\mathrm{pH}$. In general, the onset for $\mathrm{CO}$ oxidation follows the trend $\mathrm{NaOH}<\mathrm{HClO}_{4}<\mathrm{H}_{2} \mathrm{SO}_{4}$. It should be noted that the oxidation peak in $0.1 \mathrm{M}$ 
$\mathrm{NaOH}$ exhibits a significant prevawe, as described previously. ${ }^{16}$ Regarding the peak potential differences between perchloric and sulfuric acid solutions, the higher peak potential for sulfuric acid solutions is related to the specific adsorption of sulfate, ${ }^{34}$ which hinders the adsorption of the required oxygen containing species necessary for the oxidation of $\mathrm{CO}$ through the LangmuirHinshelwood mechanism. ${ }^{11}$ On the other hand, $\mathrm{OH}$ adsorption can occur easier on the defects present in the $\mathrm{CO}$ adlayer. In fact, it has been suggested that the onset potential depends on the number of those defects, ${ }^{35}$ which may explain the lower onset for the $\mathrm{CO}$ oxidation in alkaline solutions. Moreover, the appearance of the prewave has been associated to the presence of defects in the $\mathrm{CO}$ adlayer ${ }^{21}$ or $\mathrm{CO}$ oxidation on pristine $\mathrm{Pt}(111)$ surfaces with initially disordered (111) steps as observed by in situ STM. ${ }^{36}$ This relationship between the prewave and the defects in the adlayer will be considered in the next sections of this manuscript.

When (110) steps are deliberately introduced in the (111) terrace (Figure 3) changes in the onset and peak potential for $\mathrm{CO}$ oxidation occurs. In acidic solutions, the $\mathrm{CO}$ stripping process takes place in a single peak. As occurs for the $\mathrm{Pt}(111)$ electrode, the $\mathrm{CO}$ stripping peak potential in $0.5 \mathrm{M} \mathrm{H}_{2} \mathrm{SO}_{4}$ solution is ca. $0.1 \mathrm{~V}$ higher than that measured in $0.1 \mathrm{M} \mathrm{HClO}_{4}$ solution. ${ }^{34}$ When compared to the $\mathrm{Pt}(111)$ electrode, peak potentials shift to lower values (ca. $0.07 \mathrm{~V}$ for the $\mathrm{Pt}(554)$ electrode), due to the catalytic effect of the steps in the reaction. ${ }^{9}, 12$

On the other hand, the CO stripping voltammetric profile splits into multiple peaks in alkaline solutions. Those peaks are associated to the oxidation of $\mathrm{CO}$ on the different surface sites (steps and terraces sites). The lowest potential peak is related to the oxidation of $\mathrm{CO}$ on (111) terrace sites close to the step, whereas the CO oxidation on the step and on the remaining (111) terrace sites occurs in the peak at the highest potential. ${ }^{16,20}$ The double assignment of this peak can be corroborated when the stripping peak of a CO step-decorated surface is compared to that obtained for a $\mathrm{CO}$ monolayer (figure 3 - green line). CO-decorated steps were obtained by partial $\mathrm{CO}$ adlayer 
stripping, as described in detail in reference ${ }^{20}$. As can be seen, the charge under the peak at ca. $0.79 \mathrm{~V}$ for the step-decorated surface is smaller than that measured for fully covered $\mathrm{CO}$ surface, indicating that this peak also contains the contribution of the oxidation of $\mathrm{CO}$ molecules in terrace sites far from the step line. In fact, the difference in charge between both experiments is affected by the scan rate and the terrace width. ${ }^{15,21}$ The longer the terrace width and the faster the scan rate are, the larger the difference in charge for this peak between both experiments is.

The peak potential for this latter peak is equal to that measured on the $\operatorname{Pt}(111)$ electrode. It is clear, then, that the (110) steps have a positive catalytic effect in the oxidation of $\mathrm{CO}$, since the onset for the oxidation moves towards negative potential values when steps are present on the electrode surface. However, there is a significant difference between acidic and alkaline solutions. As has been already mentioned, the different behavior of the $\mathrm{CO}$ oxidation process in acidic or alkaline media is probably related to a different mobility of $\mathrm{CO}$ on the surface depending on the interfacial $\mathrm{pH} .{ }^{15-16,21}$ It has been proposed that the diffusion of $\mathrm{CO}$ on the surface is very fast in acidic solutions, so that, when $\mathrm{CO}$ close to the step is oxidized, these sites are immediately occupied by incoming $\mathrm{CO}$ molecules and the whole oxidation process occurs in a single peak. In alkaline solutions, the catalytic effect of the step is only restricted to the $\mathrm{CO}$ adsorbed on the (111) terrace sites close to the step. The proposed low diffusion rate for $\mathrm{CO}$ in alkaline solutions prevents the arrival of the $\mathrm{CO}$ molecules to the newly liberated sites, giving rise to two peaks, one related to the presence of the steps and the second one with the characteristics of the (111) infinite terraces.

These results seem to suggest that alkaline solutions are more active for the oxidation of $\mathrm{CO}$ on Pt, since the onset and peak potentials in the RHE scale are lower than those measured in acidic solutions. However, as it will be shown below, this result is mainly a consequence of the differences in the CO adlayer structure on (111) domains obtained in different electrolytic conditions and not a true catalytic effect. 


\subsection{Effect of the CO adsorption potential on its oxidation}

It has been clearly shown that the $\mathrm{CO}$ oxidation potential is affected by the potential at which the $\mathrm{CO}$ adlayer is formed ${ }^{3-5}$ For that reason, a new experiment has been carried out in which $\mathrm{CO}$ is adsorbed at $0.1 \mathrm{~V}$ in $0.5 \mathrm{M} \mathrm{H}_{2} \mathrm{SO}_{4}$ solution and transferred to a cell containing $0.1 \mathrm{M} \mathrm{NaOH}$ in which CO is oxidized. In the SHE scale, this means that CO is formed at ca. $0.03 \mathrm{~V} v s$. SHE in the sulfuric acid solution, transferred to the second cell, immersed at ca. $-0.67 \mathrm{~V} v s$. SHE and, then, oxidized. For the adlayer formed in $\mathrm{NaOH}$, the adsorption potential is ca. $-0.67 \mathrm{~V} v$ s. SHE. This way, the comparison between two layers formed at two very different SHE potentials (and interfacial charge) can be carried out. As can be seen in figure 4, the changes in the CO stripping processes are important. For the adlayer formed in $\mathrm{NaOH}$ solutions, the adsorbed $\mathrm{CO}$ reaction starts at around $0.38 \mathrm{~V}$ in the preoxidation wave and finishes at $\sim 0.9 \mathrm{~V}$. In this preoxidation wave, some small peaks are visible, probably related to the oxidation of $\mathrm{CO}$ on the small amount of defects present on the surface, ${ }^{36}$ in a similar way that $\mathrm{CO}$ oxidation is activated in the terrace sites close to the steps. These peaks are followed by another oxidation process that has a maximum current density at $\sim 0.79 \mathrm{~V}$. In case of $\mathrm{CO}$ adlayer formed in the sulfuric acid solutions, the stripping voltammetry in alkaline solution does not exhibit any pre-oxidation wave and only one peak appears at higher potentials. In both cases, the obtained $\mathrm{CO}$ coverages are equal, within the experimental error $\left(\theta_{\mathrm{CO}} \approx 0.7\right)$, suggesting that the $\mathrm{CO}$ pre-oxidation wave cannot be related to a different $\mathrm{CO}$ surface coverage and that the changes should be linked to differences in the CO adlayer structure. As aforementioned, the onset for $\mathrm{CO}$ oxidation and peak potential strongly depend on the local $\mathrm{CO}$ adlayer structure on the terrace domains and on the number of defects of the adlayer. This fact suggests that the adlayer formed at $0.03 \mathrm{~V} v s$. SHE in acidic solutions has a lower amount of structural imperfections without changing the charge associated the adlayer 
oxidation, that is, the measured $\mathrm{CO}$ coverage. Model calculations have shown that changes in the CO coverage that are well below the accuracy of the charge measurements in the voltammetry (ca. $1 \%$ ) lead to significant changes in the peak position. ${ }^{35}$

Similar experiments were carried out with the $\operatorname{Pt}(776)$ and $\operatorname{Pt}(554)$ electrodes (figures 5 and 6). As aforementioned, the voltammetric profile for $\mathrm{CO}$ stripping contains multiple peaks for the $\operatorname{Pt}(776)$ electrode (Figure 5). When the previous experiment is compared to the new one, a major change in the $\mathrm{CO}$ stripping profile in alkaline media for the layer adsorbed in acidic solution can be observed. As occurred for the $\mathrm{Pt}(111)$ electrode, the prewave is absent and the onset or $\mathrm{CO}$ oxidation has been displaced towards higher potential values. However, only the potential for first peak shifts significantly towards higher potential values (ca. $120 \mathrm{mV}$ ), whereas the second peak only moves ca. $10 \mathrm{mV}$. It is also evident that the charge density increases for the process at high potentials. This effect can be related to the slower diffusion of the $\mathrm{CO}_{\text {ads }}$ molecules towards the terrace sites close to the step. As the scan rate for these experiments is the same, the time elapsed between both peaks for the $\mathrm{CO}$ adlayer formed in sulfuric acid solutions is shorter, that is, the time from the moment the sites on the terrace close to the step are liberated and the onset for the second peak has been reduced significantly. This way, a lower number of CO molecules away from the step are able to diffuse to sites close to the lower part of the step and being oxidized. A similar effect has been observed when the scan rate for the stripping process is increased. ${ }^{15}$ It should be stressed again that the $\mathrm{CO}$ coverages for both experiments were equal within the experimental error $\left(\theta_{\mathrm{CO}} \approx 0.7\right)$.

Finally, the behavior for $\operatorname{Pt}(554)$ electrode (Fig. 6) is qualitatively identical to that observed for $\operatorname{Pt}(776)$ electrode. The only quantitative differences are related to small changes of the peak potentials and charge, which in turn depend on the step density. The peak related to the $\mathrm{CO}$ oxidation on the (111) terraces close to the step site appears only ca. at $20 \mathrm{mV}$ more positive 
potentials for the surface with the lower step density, that is the $\operatorname{Pt}(776)$. Also, the charge measured in the second peak for the $\operatorname{Pt}(554)$ is smaller because the number of sites far from the step is lower.

The comparison between the measured curves measured in $\mathrm{NaOH}$ when $\mathrm{CO}$ was dosed at $0.1 \mathrm{~V}$ in acidic solution and that obtained in $0.1 \mathrm{M} \mathrm{HClO}_{4}$ (figures $4 \mathrm{~B}$ and $6 \mathrm{~B}$ ), shows that differences in the onset potential for $\mathrm{CO}$ oxidation in both environments are minimal in the RHE scale, that is, the initial stages of adsorbed $\mathrm{CO}$ oxidation are similar in both media. It should be highlighted that, in both cases, the $\mathrm{CO}$ adlayers were formed at the same SHE potential. Once the CO oxidation process have started, the differences in the oxidation profile are then related to the slow diffusion of $\mathrm{CO}$ towards the most active sites in Pt/alkaline solution interface as compared to the Pt/acidic solution interface.

To further analyze the difference in the kinetics of $\mathrm{CO}$ oxidation when the $\mathrm{CO}$ adlayer was formed at different SHE potentials, chronoamperometric curves for the $\operatorname{Pt}(554)$ were recorded at $0.58 \mathrm{~V}$ in $0.1 \mathrm{M} \mathrm{NaOH}$ (figure 7). The transients measured for $\mathrm{CO}$ stripping at $0.58 \mathrm{~V}$ in $0.1 \mathrm{M}$ $\mathrm{NaOH}$ for the two different adlayers have different time characteristics. For the adlayer formed in 0.1 $\mathrm{M} \mathrm{NaOH}$ rapid oxidation takes place, giving rise to a peak at ca. $1 \mathrm{~s}$, whereas the adlayer formed in acid solution is more stable and has a peak at much longer times, ca. $26 \mathrm{~s}$. However, as can be seen in insert $I_{2}$ of figure 7 , the only signal that is blocked after the stripping at that potential value is that associated to the adsorption of hydrogen on the (110) step sites in both cases. A similar behavior was observed for $\operatorname{Pt}(776)$ (not shown). This fact implies that $\mathrm{CO}$ adsorbed on the terrace sites has been completely oxidized in the transient and the only $\mathrm{CO}$ remaining is that adsorbed on the step sites. In a previous work, these transients have been modeled with a nucleation and growth mechanism in which anisotropic effects are included. ${ }^{21}$ This model gives a typical tailing in the current after in the final part of the transient that can be observed in insert $I_{1}$ of figure 7 after $1 \mathrm{~s}$ for the adlayer formed at $0.1 \mathrm{~V}$ in $\mathrm{NaOH}$. For the adlayer formed in sulfuric acid, however, the 
onset and peak times are significantly longer, which is clearly associated with a much lower nucleation rate.

\subsection{In situ Fourier Transform Infrared Spectroscopy data}

These results indicate that the differences in the behavior between acid and alkaline media are only related to the different $\mathrm{CO}$ adlayer properties obtained depending on the SHE dosing potential and the different apparent diffusion rates which is also related to the different SHE potentials of the experiments. ${ }^{21}$ Additional characterization of the adlayer structures can be obtained by analyzing the FTIR spectra. From in situ FTIR measurements, although it is not possible a quantitative assignment of $\mathrm{CO}$ bonding modes at the surface due to the strong energy transfer between $\mathrm{CO}$ bands, ${ }^{6,37} \mathrm{CO}-\mathrm{CO}$ interactions can be easily shown, which in turn are sensitive to the local $\mathrm{CO}$ environment.

Figure 8 shows the in situ FTIR spectra for adsorbed $\mathrm{CO}$ at $0.1 \mathrm{~V}$ in different conditions for the $\operatorname{Pt}(111)$ electrode, and two stepped electrodes: $\operatorname{Pt}(1717$ 15) $\equiv \operatorname{Pt}(\mathrm{s})-[16(111) \times(110)]$ and $\operatorname{Pt}(443) \equiv \operatorname{Pt}(\mathrm{s})-[7(111) \times(110)]$. The $\mathrm{CO}$ adlayer was formed at $0.1 \mathrm{~V}$ in a $\mathrm{NaOH}$ solution and analyzed in same electrolyte, adsorbed at $0.1 \mathrm{~V}$ in $0.5 \mathrm{M} \mathrm{H}_{2} \mathrm{SO}_{4}$ environment and analyzed in $\mathrm{NaOH}$ solution and adsorbed at $0.1 \mathrm{~V}$ in $0.1 \mathrm{M} \mathrm{H}_{2} \mathrm{SO}_{4}$ solution and analyzed in same acidic solution. (0.1 $\mathrm{M} \mathrm{H}_{2} \mathrm{SO}_{4}$ solution was used instead of $0.5 \mathrm{M} \mathrm{H}_{2} \mathrm{SO}_{4}$ solution to prevent corrosion of the window prism. However, no significant differences with were observed in experiments between both acidic media.) The reference spectra is always recorded at $0.9 \mathrm{~V}$ in the respective solution after complete $\mathrm{CO}$ oxidation. For the top spectrum on the $\mathrm{Pt}(111)$ electrode, two broad bands at $\sim 2025 \mathrm{~cm}^{-1}$ and $\sim 1793 \mathrm{~cm}^{-1}$ assigned to the linear $\left(\mathrm{CO}^{1}\right)$ and bridge bonded $\left(\mathrm{CO}^{\mathrm{b}}\right) \mathrm{CO}$, respectively, are clearly visible. These frequencies are in agreement with previous results from Garcia and Koper for $\mathrm{Pt}(111) / \mathrm{CO}$ in alkaline media. ${ }^{19}$ These bands are strongly affected by the dipole-dipole 
coupling, ${ }^{37-38}$ and the absorption intensity is transferred towards the higher frequency band at the expense of the lower frequency band. For linear CO band, its corresponding Stark shifts is $\mathrm{d} v_{\mathrm{CO}} / \mathrm{d} E$ $=45 \mathrm{~cm}^{-1} \mathrm{~V}^{-1}$. The values for the bridge bonded $\mathrm{CO}$ are not given due to low intensity of this band, which precludes an accurate determination of its peak position. The Stark shift obtained in this case is higher than that reported previously in the literature for the same system in alkaline media (37 $\left.\mathrm{cm}^{-1} \mathrm{~V}^{-1}\right) .{ }^{19}$ Two additional bands appear in the spectra, at lower frequencies. The broad band at $\sim 1630 \mathrm{~cm}^{-1}$ is related to the $\mathrm{O}-\mathrm{H}$ bending mode of water in the thin layer ${ }^{39}$ and other band at $\sim 1400$ $\mathrm{cm}^{-1}$ is attributed to the carbonate anion, formed at the reference potential after the oxidation of $\mathrm{CO}^{40}$

When the $\mathrm{CO}$ adlayer was formed on $\mathrm{Pt}(111)$ in $\mathrm{H}_{2} \mathrm{SO}_{4}$ solution and the electrode covered by $\mathrm{CO}$ is transferred to the $\mathrm{NaOH}$ solution, where the spectra are acquired, $\mathrm{CO}^{1}$ and $\mathrm{CO}^{\mathrm{b}}$ bands appear at $\sim 2029 \mathrm{~cm}^{-1}$ and $\sim 1794 \mathrm{~cm}^{-1}$, respectively, values that are higher than those observed in the previous case. Additionally, these bands are narrower. The higher frequencies and narrower bands indicate that there are stronger $\mathrm{CO}-\mathrm{CO}$ interactions in the adlayer, which are associated to a better ordered structure. ${ }^{41}$ The corresponding Stark tuning effects for linear adsorbed CO under this condition is $\mathrm{d} v_{\mathrm{CO}} / \mathrm{d} E=33 \mathrm{~cm}^{-1} \mathrm{~V}^{-1}$. Finally, for $\mathrm{CO}$ adsorbed in acid and analyzed in acidic solutions, the spectrum shows $\mathrm{CO}^{1}$ band at $\sim 2057 \mathrm{~cm}^{-1}$ (with its respective $\mathrm{d} v_{\mathrm{CO}} / \mathrm{d} E=35 \mathrm{~cm}^{-1} \mathrm{~V}^{-1}$ ) and $\mathrm{CO}^{\mathrm{b}}$ band $\sim 1828 \mathrm{~cm}^{-1} .7$ The band frequencies and Stark effects are in perfect agreements with previous results from our laboratory in $\mathrm{HClO}_{4}$ solution ${ }^{7}$ and those from Stamenkovic et al. ${ }^{42}$ and Zou et al. ${ }^{43}$ for $\mathrm{Pt}(111) / \mathrm{CO}$ in $\mathrm{H}_{2} \mathrm{SO}_{4}$ solution. On the other hand, Akemann et al. ${ }^{44}$ report a Stark effect for $\mathrm{CO}$ on $\mathrm{Pt}(111)$ under $\mathrm{HClO}_{4}$ solution about $20 \mathrm{~cm}^{-1} \mathrm{~V}^{-1}$ and $50 \mathrm{~cm}^{-1} \mathrm{~V}^{-1}$ for $\mathrm{CO}^{1}$ and $\mathrm{CO}^{\mathrm{b}}$, respectively. In these spectra, an additional band appears at $\sim 1256 \mathrm{~cm}^{-1}$, which has been assigned to adsorbed sulfate in a three-fold coordinated symmetry site. ${ }^{45}$ Similar results were obtained for the other two electrodes, which are summarized in Table 1. 
From the FTIR results, it can be shown that the $\mathrm{CO}$ adlayer formed in acidic solution and analyzed in $\mathrm{NaOH}$ has maintained their structural characteristics when long-range (111) domains are present. For long-range (111) terraces, the Stark tuning effect for this adlayer examined in acid and alkaline conditions is the same, within the experimental error. Additionally, if the effect of the SHE potential is taken into account in the observed frequencies, it can be concluded that the band positions are in perfect agreement with those expected. For the $\operatorname{Pt}\left(\begin{array}{lll}17 & 17 & 15\end{array}\right)$ electrode (as an example, Fig. 8 and Table 1), the expected change in frequency of the $\mathrm{CO}$ band from acid to alkaline solutions is $25 \mathrm{~cm}^{-1}$. This value has been calculated using the Stark tuning slope of $\sim 34$ $\mathrm{cm}^{-1} \mathrm{~V}^{-1}$ for $\mathrm{CO}^{1}$ recorded in acid solution and using the difference in SHE potential for the corresponding $\mathrm{pH}$ change (a pH change of 12 units, is equivalent to a change in SHE potential of ca. $0.70 \mathrm{~V}$ ). The experimental difference is $24 \mathrm{~cm}^{-1}$, which is, within the experimental error, equal to the predicted value. Moreover, an excellent linear fitting to the frequencies in acidic and alkaline solutions for this adlayer is obtained for the $\operatorname{Pt}(111)$ and $\operatorname{Pt}(17,17,15)$ electrodes (figure 9). This fact indicates that the identity of the adlayer is preserved upon transferring form the acid to the alkaline solution. Additionally, the higher frequencies for this adlayer form in acidic solutions as compared to that formed in alkaline solutions is associated with a layer with higher $\mathrm{CO}-\mathrm{CO}$ interactions. Since the coverage is the same for both cases, the major difference should be then related to a lower number of defects present in the adlayer formed in acid solutions, in agreement with the proposed interpretation of the voltammetric results. For shorter (111) domains (as an example for Pt(443) in Fig. 8 and Table 1) although the frequency values are very similar, their Stark effect values suggested that short (111) domains contribute less to preserve the CO adlayer structure after transfer from the acid environment to the alkaline one. 


\section{Concluding remarks.}

The results presented here indicate that the structure of the adlayer and the mobility of CO over the surface play a significant role in the kinetics of $\mathrm{CO}$ oxidation. Moreover, both $\mathrm{CO}$ mobility and $\mathrm{CO}$ adlayer surface structure depend on the SHE electrode potential, which can be seen as the main source of the observed differences. The structure of the adlayer plays a significant role in the onset of $\mathrm{CO}$ oxidation, due to the oxidation mechanism. $\mathrm{CO}$ oxidation through a LangmuirHinshelwood mechanism requires the presence of defects so that the oxidation can start. ${ }^{11,35}$ The higher the number of defects are initially present in the adlayer, the lower the onset for oxidation is. Thus, the apparent higher catalytic activity of the Pt electrode for the oxidation of $\mathrm{CO}$ in alkaline media, which has been proposed because the lower onset for $\mathrm{CO}$ oxidation recorded in voltammetry as compared with acidic solutions, is a consequence of the a higher number of defects in the $\mathrm{CO}$ adlayer, and not a true catalytic effect. The lower number of defects (or the larger domains observed when $\mathrm{CO}$ is present in solution ${ }^{23}$ ) can be also a consequence of the different mobility of CO. In acidic environments, the high mobility of the $\mathrm{CO}$ on the surface allows the coalescence of the different domains of the ordered adlayer formed in the initial stages of $\mathrm{CO}$ adsorption, giving rise to a well-ordered adlayer. In contrast, the low mobility of the $\mathrm{CO}$ does not allow such a process, producing smaller domains and a higher number of domain boundaries, linked to a lower onset for the CO stripping process.

Once the oxidation has started, the mobility of $\mathrm{CO}$ is which determines how this process occurs (i.e., only one or several peaks appear in the voltammetric profile). If the mobility of adsorbed $\mathrm{CO}$ is high as compared to the scan rate, $\mathrm{CO}$ will diffuse over the surface and eventually will find a site in which its oxidation is favorable. Thus, a single peak is always observed. On the other hand, several peaks are observed for the low mobility case because $\mathrm{CO}$ can be only oxidized on a particular site when the proper potential is reached. It should be recalled that, for low $\mathrm{CO}$ 
coverages, whose oxidation is not affected by the presence of defects in the adlayer, $\mathrm{CO}$ oxidation in acidic solution takes place at lower potentials in alkaline media. For $\operatorname{Pt}(111)$ stepped surfaces, low CO coverages are oxidized at ca. $0.65-0.70 \mathrm{~V}$ vs RHE in acidic solutions, ${ }^{9}$ whereas similar coverages are only oxidized at ca. $0.8 \mathrm{~V}$ vs RHE in alkaline solutions. ${ }^{20}$ This different behavior can be easily explained because of the different mobility or local effects in $\mathrm{CO}$ adlayer depending on both the electrode potential or charge on electrode surface.

Additionally, the constancy in the physical properties of the $\mathrm{CO}$ adlayer with the electrode potential, as those observed in the experiments where $\mathrm{CO}$ is adsorbed in acidic solutions and transferred to alkaline media, makes possible the comparison with the UHV values. This comparison can be used in the estimation of other physical properties of the electrode, as proposed by Weaver. ${ }^{46-47}$ In these works, the pzc of the CO covered $\mathrm{Pt}(111)$ electrode was assessed using the work function measured in UHV for the $\mathrm{Pt}(111)$ electrode covered with $\mathrm{CO}$ and $\mathrm{D}_{2} \mathrm{O}^{41}$. According to the model proposed by Trasatti, ${ }^{48}$ the relationship between the work function and the $\operatorname{pzc}\left(E_{p z c}\right)$ is:

$$
E_{p z c}=\Phi / e-E_{\mathrm{Ref}}
$$

where $\Phi$ is the work function, $e$ is the elementary charge and $E_{\text {Ref }}$ the so-called "absolute" potential of the reference electrode. Using the measured value of the work function for the $\mathrm{CO}$ covered surface $(5.6 \mathrm{eV})$ and an estimation of absolute potential of the reference electrode $(4.6 \mathrm{~V})$, a value of 1.0 V was obtained. ${ }^{46}$ The value of $4.6 \mathrm{~V}$ for the absolute potential was selected because it was in the middle of the normal range of proposed values (between 4.4 and $4.8 \mathrm{~V}$ ). ${ }^{48}$ In the present case, we have found that the infrared properties of the $\mathrm{CO}$ adlayer are constant over a large potential window. Thus, these data can be used to obtain an estimation of the pzc of the CO covered electrode. The Stark effect shows that the frequencies for $\mathrm{CO}$ are very dependent on the electrode 
potential. At the pzc of for the electrode, the frequencies for $\mathrm{CO}$ should be the same than those measured in UHV, since the absolute potential for both situations is the same. For the $\operatorname{Pt}(111)$ covered with $\mathrm{CO}$ and $\mathrm{D}_{2} \mathrm{O}$, the band frequency for linear $\mathrm{CO}$ is $2089 \mathrm{~cm}^{-1}$. ${ }^{41}$ The linear regression obtained in figure 9 can be used to obtain such value. From the linear regression, the extrapolated value for the potential at which the band frequency for linear CO is $2089 \mathrm{~cm}^{-1}$ is $0.94 \mathrm{~V}$ vs. SHE. A similar result is obtained with the $\mathrm{Pt}(17,17$ 15) surface which conatians large (111) terraces. Our value is ca. $0.03 \mathrm{~V}$ lower than that proposed by Weaver. ${ }^{46}$ However, it should be stressed that the latter value requires the knowledge of the exact value of the absolute reference potential, whereas the calculation presented here does not depend on that value. In fact, a value for $E_{\text {Ref }}$ of $4.66 \mathrm{~V}$ would have given the same pzc. In conclusion, similar adlayer lead to the same interfacial properties.

Acknowledgements: M.J.S.F would like to thanks CNPq, Brazil, for financial support for his stay at Universidad de Alicante. This work has been financially supported by the MICINN (Spain) (project CTQ2010-16271) and Generalitat Valenciana (project PROMETEO/2009/045, FEDER).

\section{References}

1. Kita, H.; Shimazu, K.; Kunimatsu, K., Electrochemical Oxidation of CO on Pt in Acidic and Alkaline Solutions. Part I. Voltammetric Study on the Adsorbed Species and Effects of Aging and Sn(Iv) Pretreatment. J. Electroanal. Chem. 1988, 241, 163-179.

2. Yan, Y.-G.; Yang, Y.-Y.; Peng, B.; Malkhandi, S.; Bund, A.; Stimming, U.; Cai, W.-B., Study of CO Oxidation on Polycrystalline Pt Electrodes in Acidic Solution by Atr-Seiras. $J$. Phys. Chem. c 2011, 115, 16378-16388.

3. López-Cudero, A.; Cuesta, A.; Gutiérrez, C., Potential Dependence of the Saturation CO Coverage of Pt Electrodes: The Origin of the Pre-Peak in CO-Stripping Voltammograms. Part 1: Pt(1 1 1). J. Electroanal. Chem. 2005, 579, 1-12.

4. López-Cudero, A.; Cuesta, Á.; Gutiérrez, C., Potential Dependence of the Saturation CO Coverage of Pt Electrodes: The Origin of the Pre-Peak in CO-Stripping Voltammograms. Part 2: Pt(1 0 0). J. Electroanal. Chem. 2006, 586, 204-216. 
5. Cuesta, A.; Couto, A.; Rincón, A.; Pérez, M. C.; López-Cudero, A.; Gutiérrez, C., Potential Dependence of the Saturation CO Coverage of Pt Electrodes: The Origin of the PrePeak in CO-Stripping Voltammograms. Part 3: Pt(Poly). J. Electroanal. Chem. 2006, 586, 184195.

6. Villegas, I.; Weaver, M. J., Carbon-Monoxide Adlayer Structures on Platinum(111) Electrodes - a Synergy between in-Situ Scanning-Tunneling-Microscopy and InfraredSpectroscopy. J. Chem. Phys. 1994, 101, 1648-1660.

7. Rodes, A.; Gómez, R.; Feliu, J. M.; Weaver, M. J., Sensitivity of Compressed Carbon Monoxide Adlayers on Platinum(Iii) Electrodes to Long-Range Substrate Structure: Influence-of Monoatomic Steps. Langmuir 2000, 16, 811-816.

8. $\quad$ Feliu, J. M.; Orts, J. M.; Fernández-Vega, A.; Aldaz, A.; Clavilier, J., Electrochemical Studies in Sulphuric Acid Solutions of Adsorbed CO on Pt (111) Electrodes J. Electroanal. Chem. 1990, 296, 191-201.

9. $\quad$ Lebedeva, N. P.; Koper, M. T. M.; Herrero, E.; Feliu, J. M.; van Santen, R. A., CO Oxidation on Stepped Pt N(111) X (111) Electrodes. J. Electroanal. Chem. 2000, 487, 37-44.

10. McCallum, C.; Pletcher, D., An Investigation of the Mechanism of the Oxidation of Carbon Monoxide Adsorbed onto a Smooth Pt Electrode in Aqueous Acid. J. Electroanal. Chem. 1976, 70, 277-290.

11. Bergelin, M.; Herrero, E.; Feliu, J. M.; Wasberg, M., Oxidation of CO Adlayers on $\mathrm{Pt}(111)$ at Low Potentials: An Impinging Jet Study in H2so4 Electrolyte with Mathematical Modeling of the Current Transients. J. Electroanal. Chem. 1999, 467, 74-84.

12. Lebedeva, N. P.; Koper, M. T. M.; Feliu, J. M.; van Santen, R. A., Role of Crystalline Defects in Electrocatalysis: Mechanism and Kinetics of CO Adlayer Oxidation on Stepped Platinum Electrodes. J. Phys. Chem. B 2002, 106, 12938-12947.

13. Petukhov, A. V.; Akemann, W.; Friedrich, K. A.; Stimming, U., Kinetics of Electrooxidation of a CO Monolayer at the Platinum/Electrolyte Interface. Surf. Sci. 1998, 402, 182-186.

14. Korzeniewski, C.; Kardash, D., Use of a Dynamic Monte Carlo Simulation in the Study of Nucleation-and-Growth Models for CO Electrochemical Oxidation†. J. Phys. Chem. B 2001, 105, 8663-8671.

15. Garcia, G.; Koper, M. T. M., Stripping Voltammetry of Carbon Monoxide Oxidation on Stepped Platinum Single-Crystal Electrodes in Alkaline Solution. Phys. Chem. Chem. Phys. 2008, 10, 3802-3811.

16. Garcia, G.; Koper, M. T. M., Dual Reactivity of Step-Bound Carbon Monoxide During Oxidation on a Stepped Platinum Electrode in Alkaline Media. J. Am. Chem. Soc. 2009, 131, 5384-5385.

17. Stoffelsma, C.; Rodriguez, P.; Garcia, G.; Garcia-Araez, N.; Strmcnik, D.; Marković, N. M.; Koper, M. T. M., Promotion of the Oxidation of Carbon Monoxide at Stepped Platinum Single-Crystal Electrodes in Alkaline Media by Lithium and Beryllium Cations. J. Am. Chem. Soc. 2010, 132, 16127-16133.

18. Koper, M. T. M., Structure Sensitivity and Nanoscale Effects in Electrocatalysis. Nanoscale 2011, 3, 2054-2073.

19. Garcia, G.; Rodriguez, P.; Rosca, V.; Koper, M. T. M., Fourier Transform Infrared Spectroscopy Study of CO Electro-Oxidation on Pt(111) in Alkaline Media. Langmuir 2009, 25, 13661-13666. 
20. Farias, M. J. S.; Herrero, E.; Feliu, J. M., Site Selectivity for CO Adsorption and Stripping on Stepped and Kinked Platinum Surfaces in Alkaline Medium. J. Phys. Chem. c 2013, 117, 2903-2913.

21. Herrero, E.; Chen, Q.-S.; Hernandez, J.; Sun, S.-G.; Feliu, J. M., Effects of the Surface Mobility on the Oxidation of Adsorbed CO on Platinum Electrodes in Alkaline Media. The Role of the Adlayer and Surface Defects. Phys. Chem. Chem. Phys. 2011, 13, 16762-16771.

22. Spendelow, J. S.; Goodpaster, J. D.; Kenis, P. J. A.; Wieckowski, A., Mechanism of CO Oxidation on Pt(111) in Alkaline Media. J. Phys. Chem. B 2006, 110, 9545-9555.

23. Markovic, N. M.; Lucas, C. A.; Rodes, A.; Stamenkovic, V.; Ross, P. N., Surface Electrochemistry of CO on Pt(111): Anion Effects. Surf. Sci. 2002, 499, L149-L158.

24. Markovic, N. M.; Ross, P. N., Surface Science Studies of Model Fuel Cell

Electrocatalysts. Surf. Sci. Rep. 2002, 45, 117-229.

25. Spendelow, J. S.; Lu, G. Q.; Kenis, P. J. A.; Wieckowski, A., Electrooxidation of Adsorbed $\mathrm{CO}$ on $\mathrm{Pt}(111)$ and $\mathrm{Pt}(111) / \mathrm{Ru}$ in Alkaline Media and Comparison with Results from Acidic Media. J. Electroanal. Chem. 2004, 568, 215-224.

26. Korzeniewski, C.; Climent, V.; Feliu, J., Electrochemistry at Platinum Single Crystal Electrodes. In Electroanal. Chem., CRC Press: 2011; pp 75-170.

27. Herrero, E.; Orts, J. M.; Aldaz, A.; Feliu, J. M., Scanning Tunneling Microscopy and Electrochemical Study of the Surface Structure of $\operatorname{Pt}(10,10,9)$ and $\operatorname{Pt}(11,10,10)$ Electrodes Prepared under Different Cooling Conditions. Surf. Sci. 1999, 440, 259-270.

28. Gómez, R.; Feliu, J. M.; Aldaz, A.; Weaver, M. J., Validity of Double-Layer ChargeCorrected Voltammetry for Assaying Carbon Monoxide Coverages on Ordered Transition Metals: Comparisons with Adlayer Structures in Electrochemical and Ultrahigh Vacuum Environments. Surf. Sci. 1998, 410, 48-61.

29. Iwasita, T.; Nart, F. C.; Vielstich, W., An Ftir Study of the Catalytic Activity of a 85:15

Pt:Ru Alloy for Methanol Oxidation. Ber. Bunsen-Ges. Phys. Chem. 1990, 94, 1030.

30. Rodes, A.; Pérez, J. M.; Aldaz, A., Vibrational Spectroscopy. In Handbook of Fuel Cells Fundamentals, Technology and Applications, Vielstich, W.; Lamm, A.; Gasteiger, H. A., Eds. John Wiley \& Sons, Ltd: Chichester, 2003; Vol. 2.

31. Marinkovic, N. S.; Markovic, N. M.; Adzic, R. R., Hydrogen Adsorption on SingleCrystal Platinum-Electrodes in Alkaline-Solutions. J. Electroanal. Chem. 1992, 330, 433-452.

32. Schmidt, T. J.; Ross, P. N.; Markovic, N. M., Temperature-Dependent Surface

Electrochemistry on Pt Single Crystals in Alkaline Electrolyte: Part 1: CO Oxidation. J. Phys.

Chem. B 2001, 105, 12082-12086.

33. van der Niet, M. J. T. C.; Garcia-Araez, N.; Hernández, J.; Feliu, J. M.; Koper, M. T. M., Water Dissociation on Well-Defined Platinum Surfaces: The Electrochemical Perspective. Catal. Today 2013, 202, 105-113.

34. Herrero, E.; Alvarez, B.; Feliu, J. M.; Blais, S.; Radovic-Hrapovic, Z.; Jerkiewicz, G., Temperature Dependence of the COads Oxidation Process on $\operatorname{Pt}(111) \operatorname{Pt}(100)$, and $\operatorname{Pt}(110)$ Electrodes. J. Electroanal. Chem. 2004, 567, 139-149.

35. Angelucci, C. A.; Herrero, E.; Feliu, J. M., Modeling CO Oxidation on Pt(111)

Electrodes. Journal of Physical Chemistry C 2010, 114, 14154-14163.

36. Inukai, J.; Tryk, D. A.; Abe, T.; Wakisaka, M.; Uchida, H.; Watanabe, M., Direct Stm Elucidation of the Effects of Atomic-Level Structure on $\mathrm{Pt}(111)$ Electrodes for Dissolved CO Oxidation. J. Am. Chem. Soc. 2013, 135, 1476-1490. 
37. Severson, M. W.; Stuhlmann, C.; Villegas, I.; Weaver, M. J., Dipole-Dipole Coupling Effects Upon Infrared-Spectroscopy of Compressed Electrochemical Adlayers - Application to the Pt(111)/CO System. J. Chem. Phys. 1995, 103, 9832-9843.

38. Persson, B. N. J.; Ryberg, R., Vibrational Interaction between Molecules Adsorbed on a Metal Surface: The Dipole-Dipole Interaction. Phys. Rev. B 1981, 24, 6954-6970.

39. Iwasita, T.; Nart, F. C., In Situ Infrared Spectroscopy at Electrochemical Interfaces. Prog. Surf. Sci. 1997, 55, 271-340.

40. Iwasita, T.; Rodes, A.; Pastor, E., Vibrational Spectroscopy of Carbonate Adsorbed on $\operatorname{Pt}(111)$ and Pt(110) Single-Crystal Electrodes. J. Electroanal. Chem. 1995, 383, 181-189.

41. Kizhakevariam, N.; Villegas, I.; Weaver, M. J., Infrared-Spectroscopy of Model Electrochemical Interfaces in Ultrahigh-Vacuum - Roles of Adsorbate and Cation Double-Layer Hydration in the Pt(111) Carbon-Monoxide Aqueous System. J. Phys. Chem. 1995, 99, 76777688.

42. $\quad$ Stamenkovic, V.; Chou, K. C.; Somorjai, G. A.; Ross, P. N.; Markovic, N. M., Vibrational Properties of $\mathrm{CO}$ at the $\mathrm{Pt}(111)$-Solution Interface: The Anomalous Stark-Tuning Slope. J. Phys. Chem. B 2005, 109, 678-680.

43. Zou, S. Z.; Weaver, M. J., Potential-Dependent Metal-Adsorbate Stretching Frequencies for Carbon Monoxide on Transition-Metal Electrodes: Chemical Bonding Versus Electrostat Ic Field Effects. J. Phys. Chem. 1996, 100, 4237-4242.

44. Akemann, W.; Friedrich, K. A.; Stimming, U., Potential-Dependence of CO Adlayer Structures on $\mathrm{Pt}(111)$ Electrodes in Acid Solution: Evidence for a Site Selective Charge Transfer. J. Chem. Phys. 2000, 113, 6864-6874.

45. Iwasita, T.; Nart, F. C.; Rodes, A.; Pastor, E.; Weber, M., Vibrational Spectroscopy at the Electrochemical Interface. Electrochim. Acta 1995, 40, 53-59.

46. Weaver, M. J., Potentials of Zero Charge for Platinum(111)-Aqueous Interfaces: A Combined Assessment from in-Situ and Ultrahigh-Vacuum Measurements. Langmuir 1998, 14, 3932-3936.

47. Gómez, R.; Climent, V.; Feliu, J. M.; Weaver, M. J., Dependence of the Potential of Zero Charge of Stepped Platinum (111) Electrodes on the Oriented Step-Edge Density:

Electrochemical Implications and Comparison with Work Function Behavior. J. Phys. Chem. B 2000, 104, 597-605.

48. Trasatti, S., Structure of the Metal/Electrolyte Solution Interface: New Data for Theory. Electrochim. Acta 1991, 36, 1659-1667. 
Table 1. Frequencies of adsorbed $\mathrm{CO}$ at $0.100 \mathrm{~V}$ and their corresponding Stark tuning slopes for adsorbed $\mathrm{CO}$ on different platinum single crystal electrodes in different conditions.

\begin{tabular}{|c|c|c|c|}
\hline Electrodes & $v \mathrm{Co} / \mathrm{cm}^{-1}$ & $v \mathrm{co}^{\mathrm{b}} / \mathrm{cm}^{-1}$ & $\mathrm{~d} v \mathrm{co}^{1} / \mathrm{d} E / \mathrm{cm}^{-1} \mathrm{~V}^{-1}$ \\
\hline $\operatorname{Pt}(111)^{a}$ & 2025 & 1795 & +45 \\
\hline $\operatorname{Pt}(111)^{b}$ & 2029 & 1794 & +33 \\
\hline $\operatorname{Pt}(111)^{c}$ & 2057 & 1828 & +35 \\
\hline $\operatorname{Pt}(171715)^{a}$ & 2018 & 1792 & +47 \\
\hline $\operatorname{Pt}(171715)^{b}$ & 2037 & 1830 & +42 \\
\hline $\operatorname{Pt}(171715)^{c}$ & 2061 & 1827 & +34 \\
\hline $\operatorname{Pt}(443)^{a}$ & 2012 & 1827 & +91 \\
\hline $\operatorname{Pt}(443)^{b}$ & 2033 & 1839 & +49 \\
\hline $\operatorname{Pt}(443)^{c}$ & 2062 & 1831 & +35 \\
\hline
\end{tabular}

${ }^{a}$ Adsorbed in $0.1 \mathrm{M} \mathrm{NaOH}$ examined in $0.1 \mathrm{M} \mathrm{NaOH}$.

${ }^{b}$ Adsorbed in $0.5 \mathrm{M} \mathrm{H}_{2} \mathrm{SO}_{4}$ and examined in $0.1 \mathrm{M} \mathrm{NaOH}$.

${ }^{c}$ Adsorbed in $0.1 \mathrm{M} \mathrm{H}_{2} \mathrm{SO}_{4}$ and examined in $0.1 \mathrm{M} \mathrm{H}_{2} \mathrm{SO}_{4}$. 


\section{Figures}

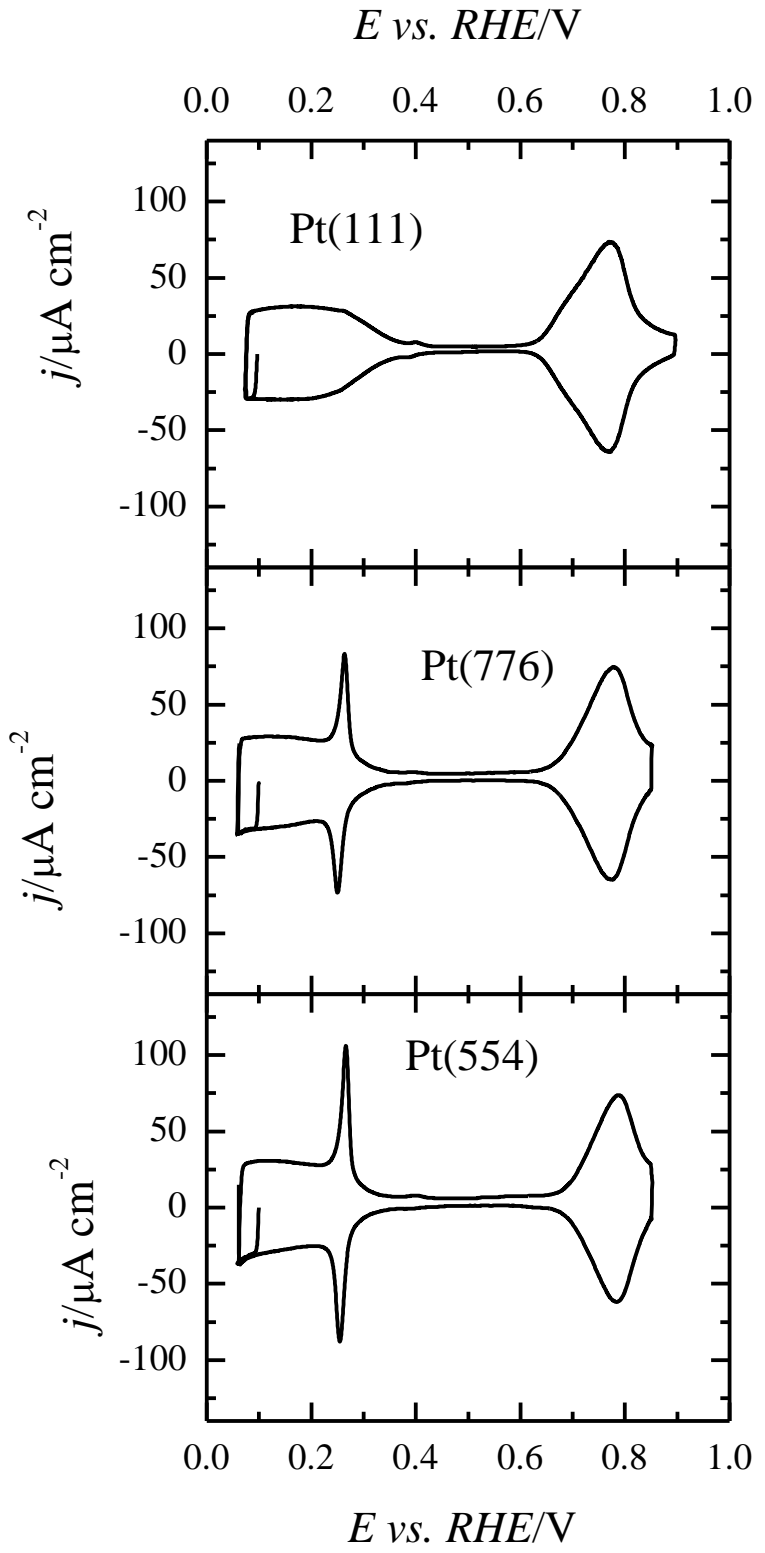

Figure 1.Voltammetric profiles for platinum single crystal electrodes in $0.1 \mathrm{M} \mathrm{NaOH}$. Scan rate: $0.05 \mathrm{~V} \mathrm{~s}^{-1}$. 


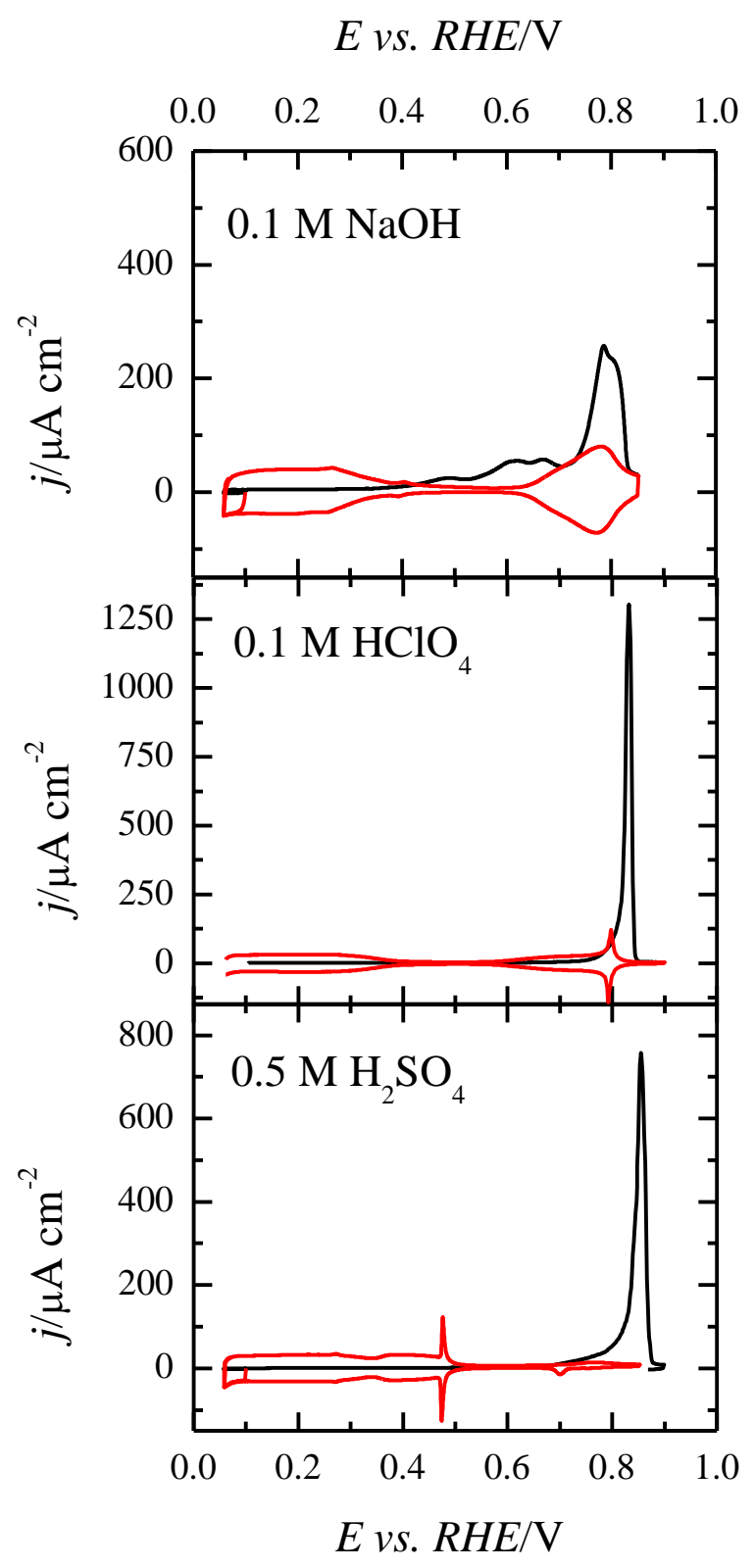

Figure 2. Voltammetric profiles for $\mathrm{CO}$ stripping (full line) and the clean surface after $\mathrm{CO}$ oxidation (dashed line) on a $\mathrm{Pt}(111)$ electrode in different electrolytic solutions. In all cases, $\mathrm{CO}$ has been adsorbed at $0.1 \mathrm{~V}$ in the same electrolytic solution. Scan rate: $0.05 \mathrm{~V} \mathrm{~s}^{-1}$ 


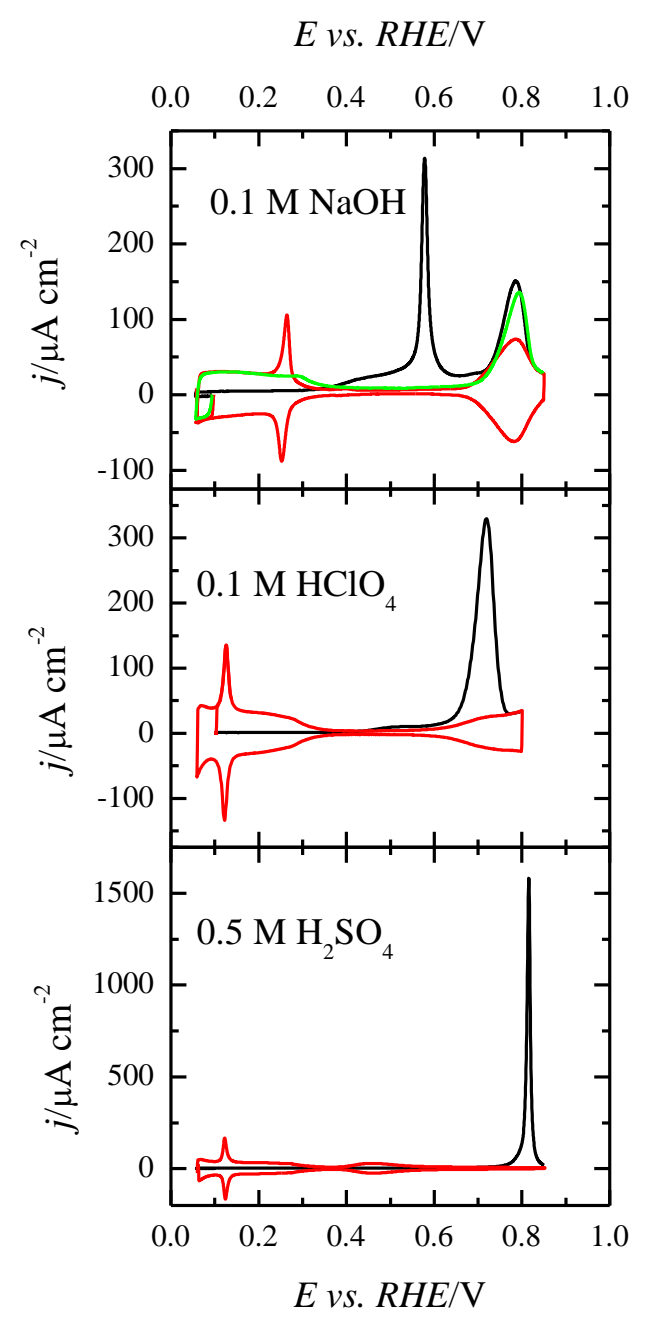

Figure 3. Voltammetric profiles for $\mathrm{CO}$ stripping (black line) and the clean surface after $\mathrm{CO}$ oxidation (red line) on a Pt(554) electrode in different electrolytic solutions. In all cases, CO has been adsorbed at $0.1 \mathrm{~V}$ in the same electrolytic solution. The green line in the top panel represents the voltammetric profile for $\mathrm{CO}$ stripping when $\mathrm{CO}$ is only adsorbed on the step sites. Scan rate: $0.05 \mathrm{~V} \mathrm{~s}^{-1}$. 


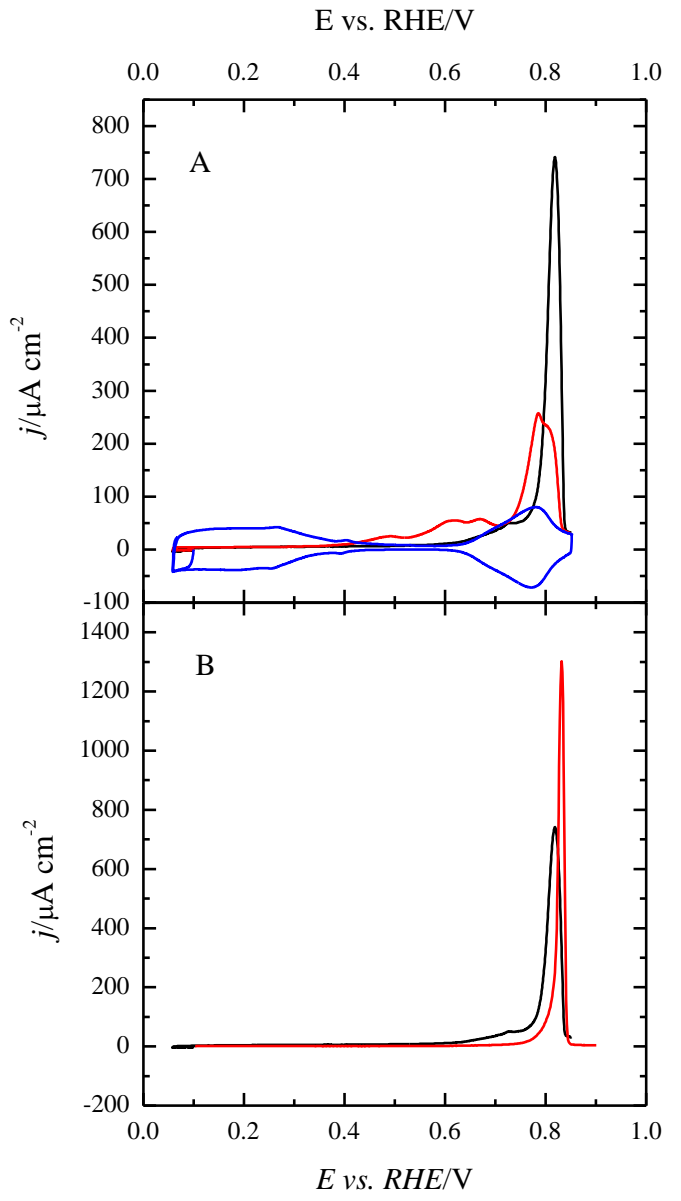

Figure 4. A) Voltammetric profile on a $\mathrm{Pt}(111)$ electrode for $\mathrm{CO}$ stripping in $0.1 \mathrm{M} \mathrm{NaOH}$ for $\mathrm{CO}$ adsorbed at $0.1 \mathrm{~V}$ in $0.5 \mathrm{M} \mathrm{H}_{2} \mathrm{SO}_{4}$ (black line) and for $\mathrm{CO}$ adsorbed at $0.1 \mathrm{~V}$ in $0.1 \mathrm{M}$ $\mathrm{NaOH}$ (red line). The blue line shows the profile of the $\mathrm{Pt}(111)$ electrode after $\mathrm{CO}$ stripping. B) Voltammetric profile on a $\mathrm{Pt}(111)$ electrode for $\mathrm{CO}$ stripping in $0.1 \mathrm{M} \mathrm{NaOH}$ for $\mathrm{CO}$ adsorbed at $0.1 \mathrm{~V}$ in $0.5 \mathrm{M} \mathrm{H}_{2} \mathrm{SO}_{4}$ (black line) and for $\mathrm{CO}$ stripping in $0.1 \mathrm{M} \mathrm{HClO}_{4}$ for $\mathrm{CO}$ adsorbed at $0.1 \mathrm{~V}$ in $0.1 \mathrm{M} \mathrm{HClO}_{4}$ (red line). Scan rate: $0.05 \mathrm{~V} \mathrm{~s}^{-1}$. 


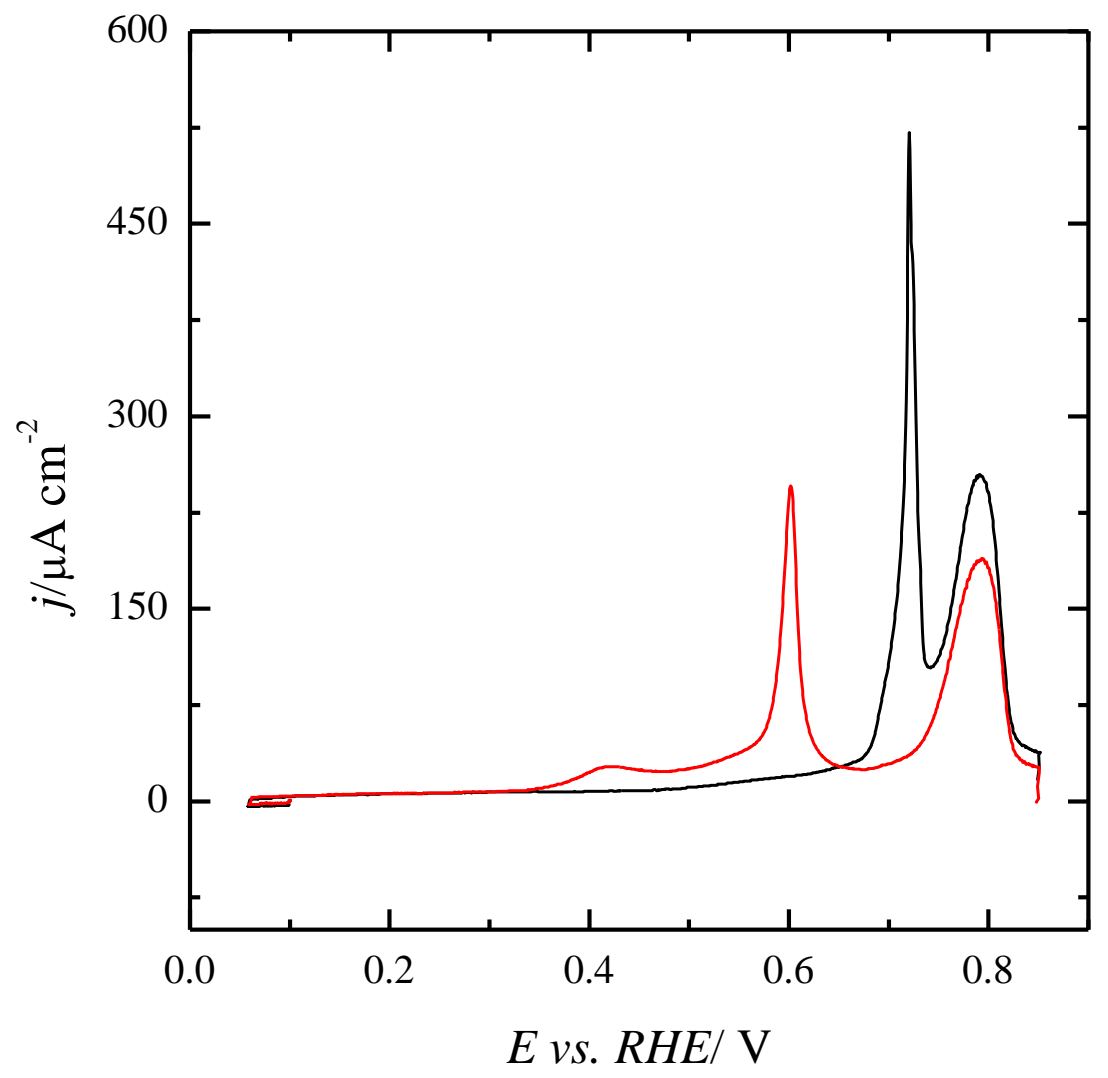

Figure 5. Voltammetric profile on a $\mathrm{Pt}(776)$ electrode for $\mathrm{CO}$ stripping in $0.1 \mathrm{M} \mathrm{NaOH}$ for $\mathrm{CO}$ adsorbed at $0.1 \mathrm{~V}$ in $0.5 \mathrm{M} \mathrm{H}_{2} \mathrm{SO}_{4}$ (black line) and for $\mathrm{CO}$ adsorbed at $0.1 \mathrm{~V}$ in $0.1 \mathrm{M}$ $\mathrm{NaOH}$ (red line). Scan rate: $0.05 \mathrm{~V} \mathrm{~s}^{-1}$. 


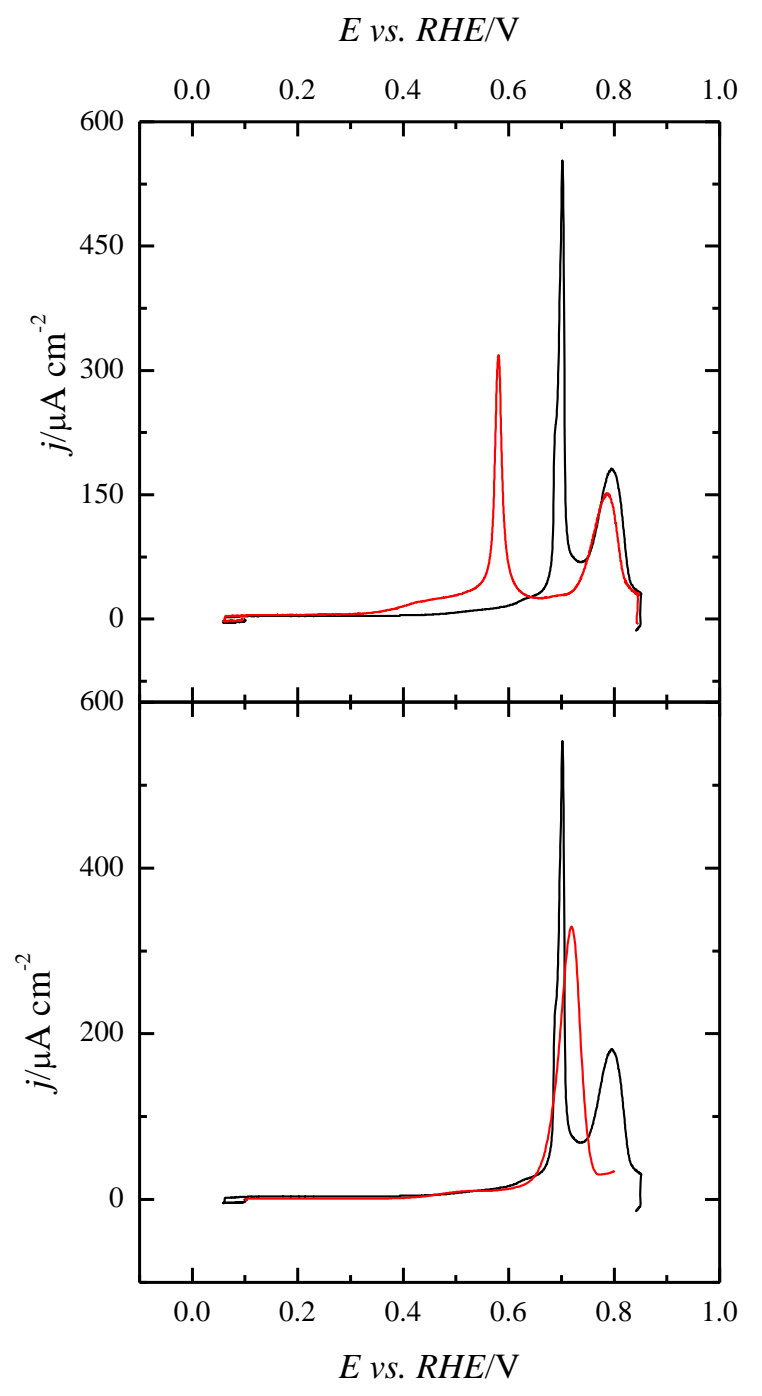

Figure 6. A) Voltammetric profile on a $\mathrm{Pt}(554)$ electrode for $\mathrm{CO}$ stripping in $0.1 \mathrm{M} \mathrm{NaOH}$ for $\mathrm{CO}$ adsorbed at $0.1 \mathrm{~V}$ in $0.5 \mathrm{M} \mathrm{H}_{2} \mathrm{SO}_{4}$ (black line) and at $0.1 \mathrm{~V}$ in $0.1 \mathrm{M} \mathrm{NaOH}$ (red line). B) Voltammetric profile on a $\mathrm{Pt}(554)$ electrode for $\mathrm{CO}$ stripping in $0.1 \mathrm{M} \mathrm{NaOH}$ for $\mathrm{CO}$ adsorbed at $0.1 \mathrm{~V}$ in $0.5 \mathrm{M} \mathrm{H}_{2} \mathrm{SO}_{4}$ (black line) and for $\mathrm{CO}$ stripping in $0.1 \mathrm{M} \mathrm{HClO}_{4}$ for $\mathrm{CO}$ adsorbed at $0.1 \mathrm{~V}$ in $0.1 \mathrm{M} \mathrm{HClO}_{4}$ (red line). Scan rate: $0.05 \mathrm{~V} \mathrm{~s}^{-1}$. 


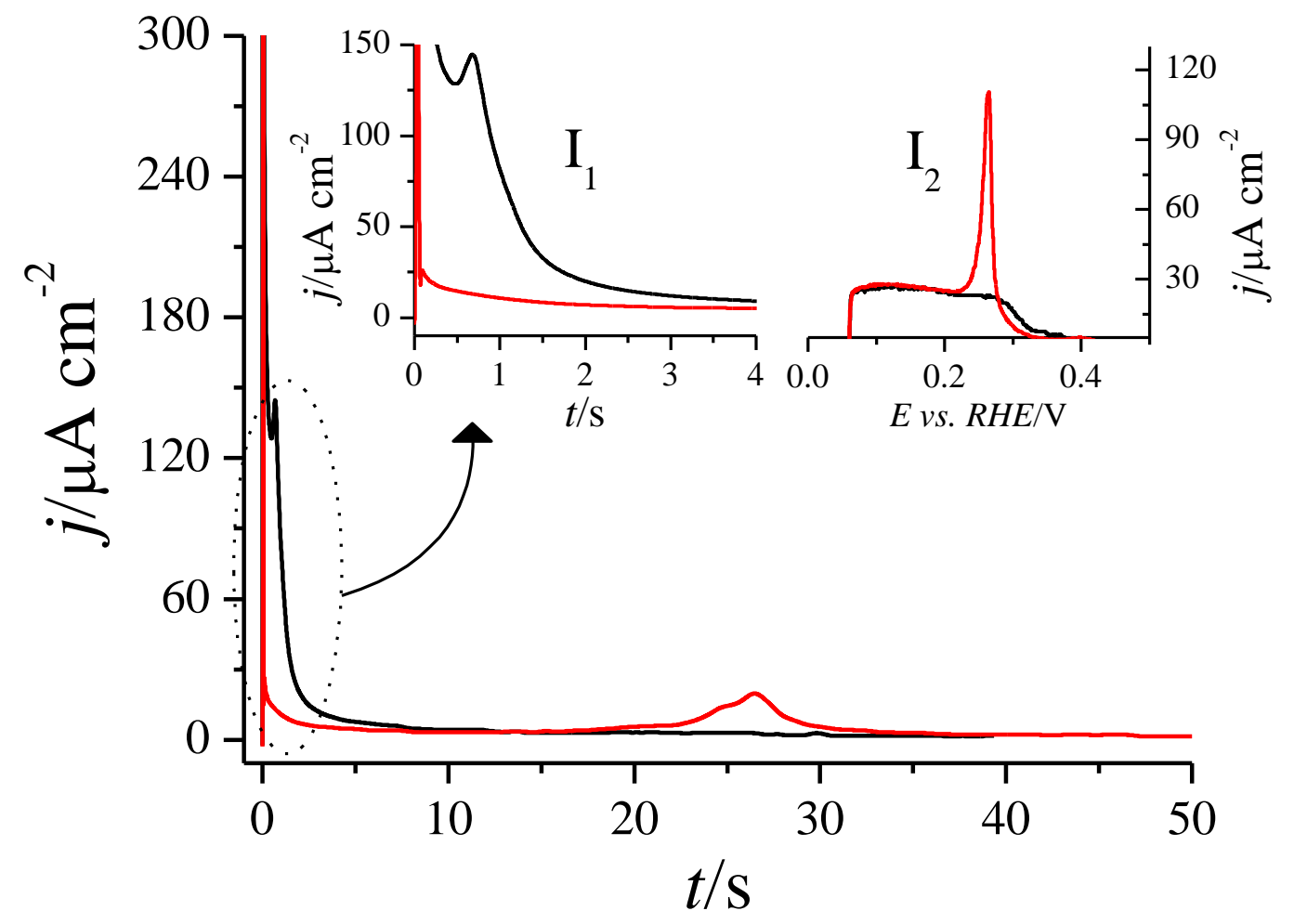

Figure 7. Current transient for $\mathrm{CO}$ stripping at $0.58 \mathrm{~V}$ on a $\mathrm{Pt}(554)$ electrode in $0.1 \mathrm{M} \mathrm{NaOH}$ for $\mathrm{CO}$ dosed at $0.1 \mathrm{~V}$ in $0.1 \mathrm{M} \mathrm{NaOH}$ (black line) and for $\mathrm{CO}$ dosed at $0.1 \mathrm{~V}$ in $0.5 \mathrm{M} \mathrm{H}_{2} \mathrm{SO}_{4}$ (red line). Insert: $\mathrm{I}_{1}$ ) Magnification of the initial part of the transient. $\mathrm{I}_{2}$ ) Voltammetric profile of the $\operatorname{Pt}(554)$ electrode after the transients (black line) and the clean surface (red line). 


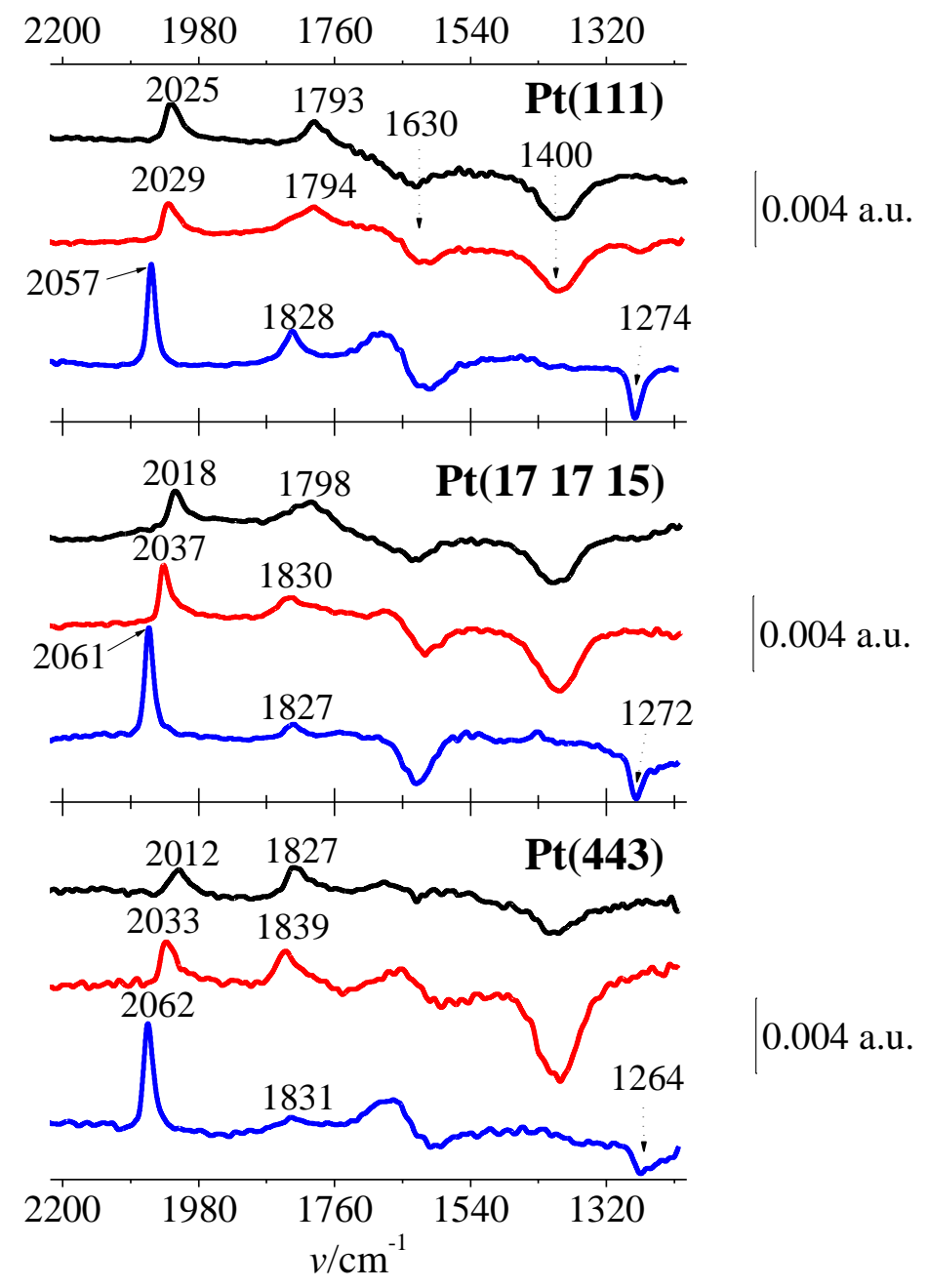

Figure 8. In situ FTIR spectra recorded for full CO monolayer for different Pt electrodes. Black line: $\mathrm{CO}$ adsorbed at $0.1 \mathrm{~V}$ in $0.1 \mathrm{M} \mathrm{NaOH}$ and spectra acquired at $0.1 \mathrm{~V}$ in $\mathrm{NaOH}$. Red line: $\mathrm{CO}$ adsorbed at $0.1 \mathrm{~V}$ in $0.5 \mathrm{M} \mathrm{H}_{2} \mathrm{SO}_{4}$ and spectra acquired at $0.1 \mathrm{~V}$ in $\mathrm{NaOH}$. Blue line: $\mathrm{CO}$ adsorbed at $0.1 \mathrm{~V}$ in $0.1 \mathrm{M} \mathrm{H}_{2} \mathrm{SO}_{4}$ and spectra acquired at $0.1 \mathrm{~V}$ in $0.1 \mathrm{M} \mathrm{H}_{2} \mathrm{SO}_{4}$. The reference spectra was always measured at $0.90 \mathrm{~V}$ in the respective solution. 

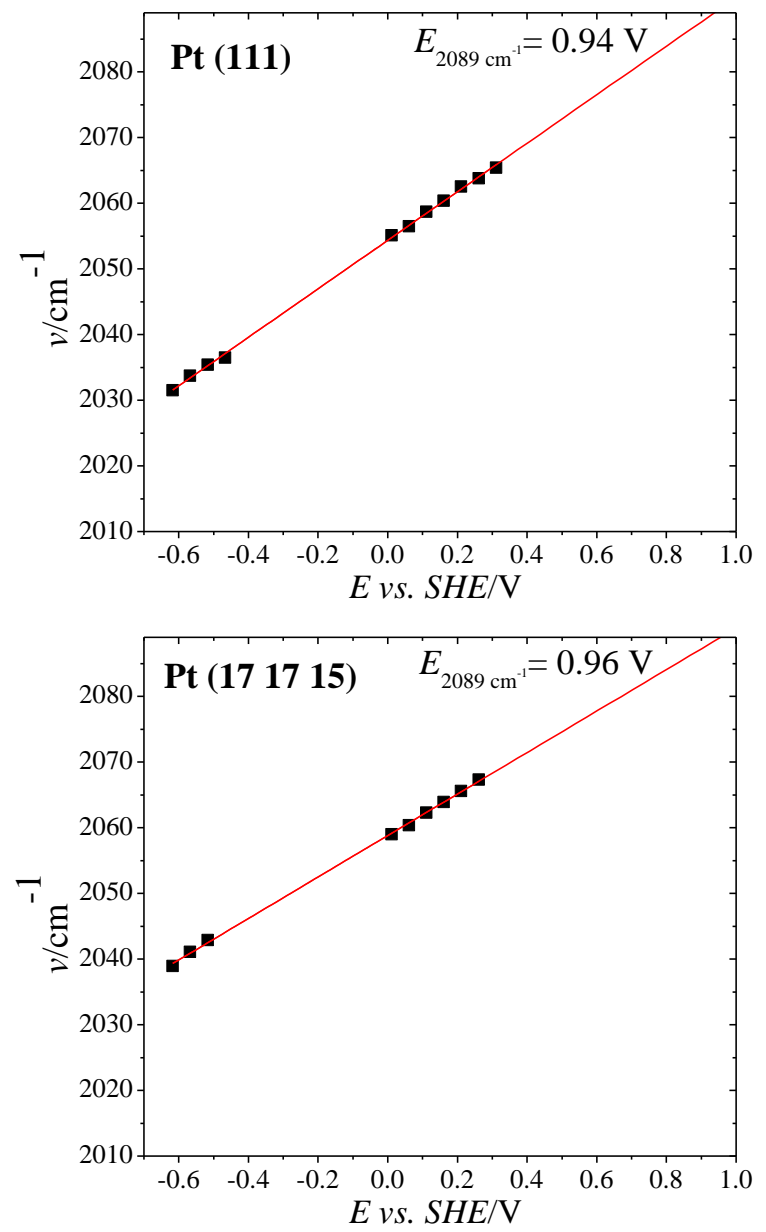

Figure 9. Frequencies for linear adsorbed CO vs. electrode potential (vs. SHE) for a CO layer formed at $0.1 \mathrm{~V}$ in $\mathrm{H}_{2} \mathrm{SO}_{4}$ solution studied both in acidic and alkaline solutions. The linear fits are also included, indicating the potential at which the extrapolated frequency would be $2089 \mathrm{~cm}^{-1}$. 


\section{TOC}

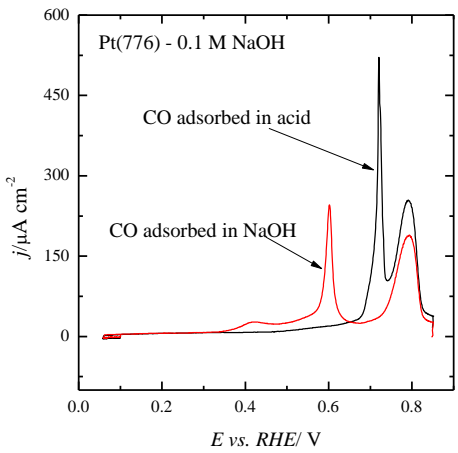

